\title{
Determinação do Teor de Água de Cactáceas pelos Métodos Padrão em Estufa e Micro-Ondas
}

\author{
José Anderson Machado Oliveira* (Mestrando em Ciências Naturais e Biotecnologia na Universidade Federal de \\ Campina Grande - UFCG/CES); \\ Antônio Daniel Buriti de Macedo (Graduando em Química na Universidade Federal de Campina Grande - \\ UFCG/CES); \\ José Leonardo Costa Raulino (Mestrando em Ciências Naturais e Biotecnologia na Universidade Federal de \\ Campina Grande - UFCG/CES); \\ Anamélia de Medeiros Dantas Raulino (Graduanda em Química na Universidade Federal de Campina Grande - \\ UFCG/CES); \\ Renato Alexandre Costa de Santana (Prof. Ad. da UABQ e do PPGCNBiotec na Universidade Federal de \\ Campina Grande - UFCG/CES); \\ Ana Regina Nascimento Campos (Profa. Ad. da UABQ e do PPGCNBiotec na Universidade Federal de \\ Campina Grande - UFCG/CES). \\ *Email: jmo.anderson@gmail.com
}

\section{Resumo:}

A determinação do teor de água em forragens frescas e silagens é um dos procedimentos mais utilizados em pesquisas sobre forragens utilizadas para alimentação animal. As dificuldades encontradas neste tipo de análise, geralmente, estão relacionadas à separação incompleta da água do produto, decomposição do produto e perda de substâncias voláteis. Este trabalho teve por objetivo comparar os métodos de determinação do teor de água utilizando o forno de micro-ondas e o método padrão em estufa em quatro cactáceas: palma forrageira (Opuntia ficus-indica Mill), mandacaru (Cereus jamacaru), facheiro ( Pilosocereus pachycladus) e xiquexique (Pilosocereus gounellel). Após coletadas, as amostras foram tratadas (trituradas e cortadas em pedaços) e submetidas a dois métodos de determinação do teor de água. A determinação do teor de água utilizando o forno de micro-ondas apresenta-se como uma alternativa viável ao método convencional de secagem por estufa, sendo as principais vantagens à redução no consumo de energia e a significativa redução no tempo de secagem, que é de 24 horas no procedimento utilizando a estufa e 18 minutos quando a secagem é feita por micro-ondas.

Palavras-chave: Forragem; Secagem; Alimentação animal. 


\section{I ntrodução}

Os métodos utilizados para conservação e estocagem de forragens podem afetar diretamente o valor nutricional do alimento. Este fato pode ser explicado devido aos procedimentos adotados durante a produção e processamento da ração, além das reações bioquímicas e processos microbiológicos que ocorrem durante o processo de produção das forragens. Assim, as alterações sofridas pelo alimento durante as etapas de produção: recolhimento, secagem e estocagem, influenciarão diretamente na composição química e nutricional da forragem produzida (JOBIM et al., 2007).

Um dos principais procedimentos utilizados em pesquisas sobre forragiculturas é a determinação do teor de água das forragens frescas, depois de passarem por algum processo de estocagem. As condições utilizadas durante a secagem de forragens afeta diretamente a sua qualidade nutricional, dessa forma, a maneira como o material vegetal é processado torna-se crucial para inibir ou ao menos diminuir as possíveis reações bioquímicas e microbiológicas que podem afetar e degradar os tecidos durante o armazenamento dessas forragens, sendo, também, necessária para avaliar as quantidades de nutrientes consumidos pelos animais (LACERDA; FREITAS; SILVA, 2009).

Dentre as diferentes técnicas utilizadas para determinar ou quantificar o teor de água em forragens aplicadas à alimentação animal destaca-se a utilização do forno com a tecnologia de microondas, convencional (doméstico) ou modificado, esta tecnologia pode ser utilizada nos mais diferentes tipos de forragens devido à rapidez de obtenção dos resultados, além da precisão obtida em comparação com os métodos tradicionais como o método padrão em estufa, que além de utilizar temperaturas consideravelmente elevadas $\left(105^{\circ} \mathrm{C}\right)$ demanda um tempo considerável para obtenção dos resultados (24 horas em média), diferentemente do método com a utilização do forno de micro-ondas onde, devido à tecnologia de aquecimento utilizada pela técnica, permite a obtenção de resultados satisfatórios com um tempo consideravelmente menor, de 10 a 20 minutos em média dependendo da forragem utilizada (SOUZA; PRIMAVESI, 2008).

As cactáceas são espécies nativas das Américas, adaptadas a ambientes áridos e apresentam características, morfológicas e fisiológicas, peculiares. Dentre estas características destacam-se a ocorrência de caules modificados, com a presença de clorofila e grande quantidade de água armazenada em seu interior formando os cladódios. Essa especialização geralmente é acompanhada pela diferenciação entre as folhas e espinhos, que protegem a planta contra predadores e contra a perda de água armazenada. Culturalmente são plantas utilizadas na alimentação animal em regiões com baixa pluviosidade anual, porém, sem passar por um tratamento adequado de processamento e estocagem, sendo retirados apenas os espinhos antes do fornecimento como alimentação animal em períodos de escassez (ZAPPI et al., 2011).

Neste trabalho, realizado no Laboratório de Bioquímica e Biotecnologia de Alimentos da Universidade Federal de Campina Grande, Centro de Educação e Saúde (UFCG/CES), foram comparados os métodos de determinação do teor de água utilizando o método padrão em estufa e forno de micro-ondas convencional em diferentes cactáceas utilizadas para alimentação animal em zonas semiáridas do Nordeste brasileiro, visando desenvolver uma metodologia alternativa viável.

\section{Metodologia}

\subsection{Preparação das amostras}

As cactáceas utilizadas neste estudo foram as seguintes: palma forrageira (Opuntia ficus-indica Mill), mandacaru (Cereus jamacaru), facheiro (Pilosocereus pachycladus) e xiquexique (Pilosocereus gounellei), coletados em janeiro de 2015, no sítio Bom Sucesso, município de Sossego localizado na microrregião do curimataú ocidental do estado da Paraíba, região Nordeste de Brasil.

As cactáceas estudadas passaram por dois tipos de tratamentos prévios antes da determinação do teor de água. As amostras foram trituradas em liquidificador doméstico até obtenção de uma mucilagem apresentando uma consistência pastosa (Figura 1), e as amostras também foram cortadas com faca de aço inox em pedaços de aproximadamente $1 \mathrm{~cm}$ (Figura 2). Estes procedimentos tiveram por objetivo avaliar a influência do tratamento prévio das amostras no processo de secagem. 


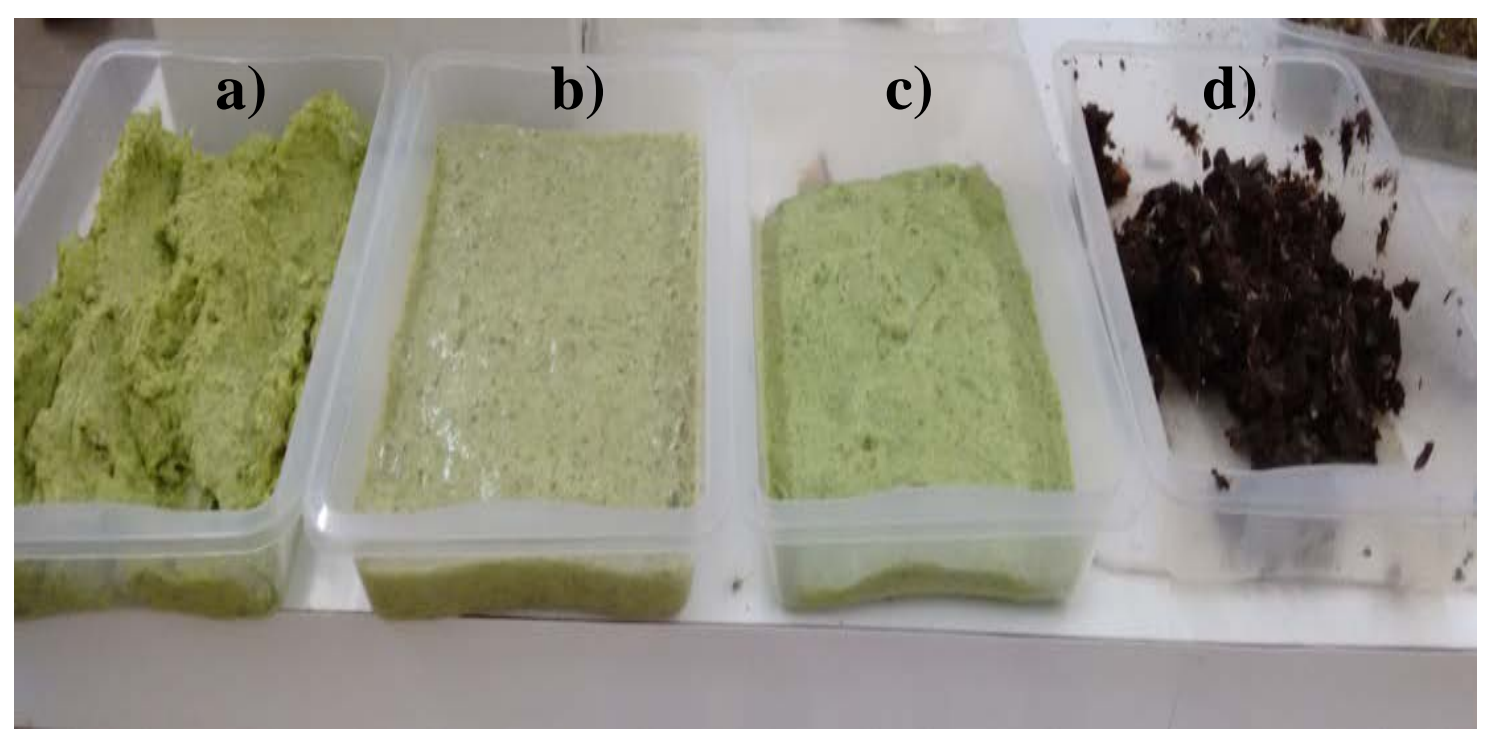

Figura 1. Mucilagem: a) Palma forrageira, b) Xiquexique, c) Mandacaru e d) Facheiro. Fonte: Arquivo pessoal.

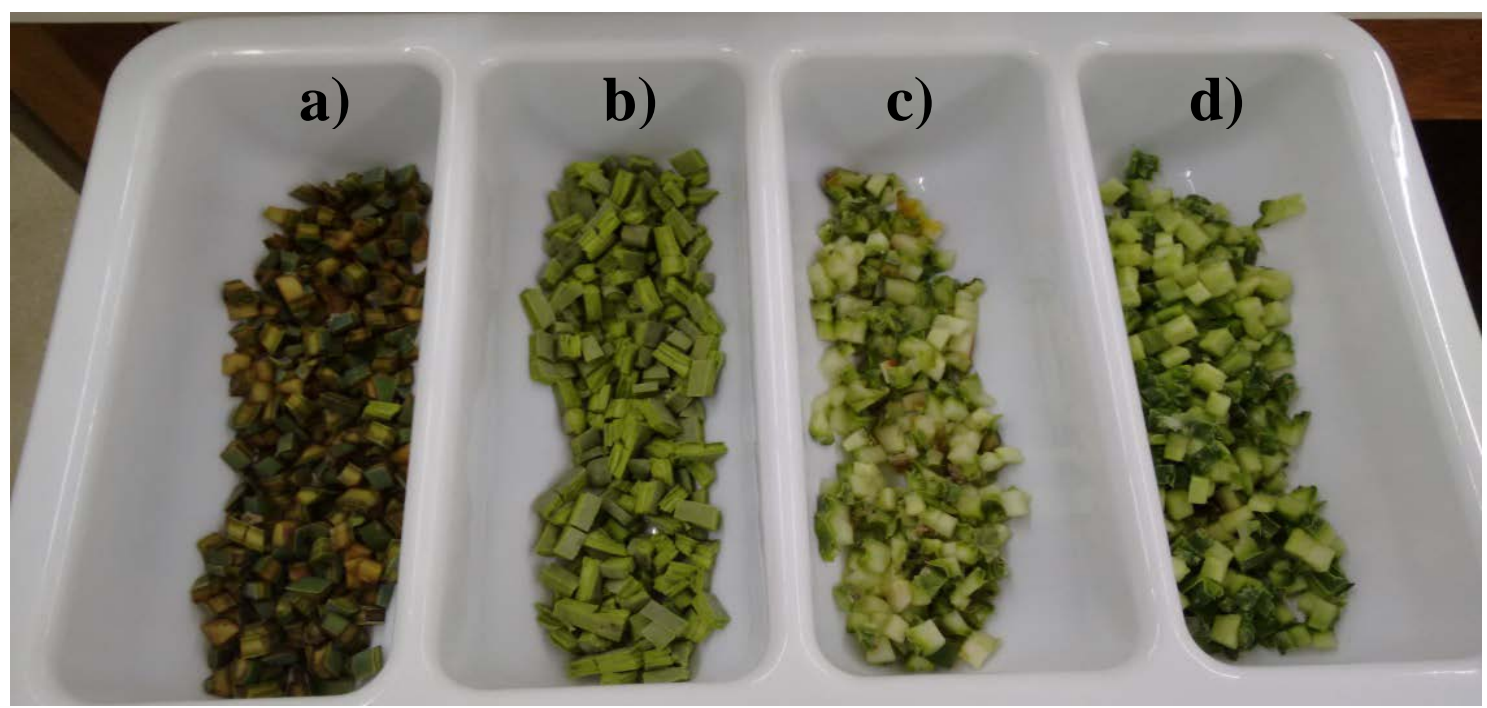

Figura 2. Cactáceas cortadas: a) Facheiro, b) Palma forrageira, c) Xiquexique e d) Mandacaru.

Fonte: Arquivo pessoal.

\subsection{Mapeamento térmico do forno de micro-ondas}

Os fornos de micro-ondas domésticos não possuem uma distribuição uniforme da radiação em seu interior, pois eles produzem interferências entre as micro-ondas e, com isso, algumas partes do forno recebem uma maior incidência de ondas que outras, causando um aquecimento diferenciado de acordo com a posição onde o material é colocado. Antes da utilização do FMO para determinação do teor de água das cactáceas foi realizado o mapeamento térmico da cavidade do forno, calibração da potência real de trabalho e testes de reprodutibilidade dos resultados com a finalidade de padronizar os dados obtidos (BARBOZA et al., 2001).

Para determinar o ponto de maior incidência da irradiação na cavidade interna do FMO e utilizar esse dado posteriormente para calibração da potência real do forno e determinação do teor de água das cactáceas, foi realizado o mapeamento da distribuição da radiação utilizando o procedimento de secagem de solução aquosa de $\mathrm{CoCl}_{2}$ (ROSINI; NASCENTES; NÓBREGA, 2004).

Para realização deste mapeamento utilizou-se uma solução aquosa de $\mathrm{CoCl}_{2} \cdot 6 \mathrm{H}_{2} \mathrm{O}(4 \% \mathrm{~m} / \mathrm{v})$ e papel toalha absorvente. Primeiramente, recortou-se o papel toalha com o mesmo diâmetro do prato giratório do FMO (aproximadamente $27 \mathrm{~cm}$ de diâmetro). Em seguida o papel foi fixado no prato e 
embebido com a solução de $\mathrm{CoCl}_{2}$, por fim, irradiou-se à potência máxima (100\%) do forno por um tempo de 60 segundos. Após a realização do experimento observou-se as regiões de maior irradiação pela mudança na coloração apresentada pela solução de $\mathrm{CoCl}_{2}$. O experimento foi realizado com o prato girando e com o prato fixo na cavidade do FMO (ROSINI et al., 2004).

\subsection{Calibração do forno de micro-ondas}

Geralmente a potência máxima fornecida pelos fabricantes de fornos de micro-ondas domésticos é de 700 W, porém, na prática observa-se uma discrepância entre a potência indicada e a potência real de trabalho do forno utilizado. Dessa forma, para obtenção de melhores resultados deve-se conhecer o valor da temperatura e da potência real de trabalho do forno que será utilizado por meio de um ajuste na potência do FMO e no tempo de cada etapa da secagem (BARBOZA et al., 2001).

A determinação da potência do forno foi realizada pela medida indireta da elevação da temperatura da água por um tempo estabelecido. Em um béquer de polipropileno, material que não absorve significativamente energia de micro-ondas, foi colocado $1 \mathrm{~L}$ de água, com temperatura inicial de $23 \pm 2{ }^{\circ} \mathrm{C}$, posicionado no local de maior incidência de radiação da cavidade do forno. O aquecimento foi realizado por 120 segundos, nas potências programadas de 100, 80, 60, 40, 20 \%; após o aquecimento registrou-se a temperatura final rapidamente. Os experimentos de calibração foram realizados em triplicata (SOUZA; NOGUEIRA; RASSINI, 2002).

O cálculo da potência real de trabalho do FMO foi realizado conforme Equação 1.

$\mathbf{P}=\frac{\mathrm{K} \mathrm{Cp} \mathbf{m}(\Delta \mathbf{T})}{\mathbf{t}}$

Onde $\mathbf{P}$ representa a potência real de trabalho $\left(\mathrm{W}=\mathrm{J} . \mathrm{s}^{-1}\right), \mathbf{K}$ representa o fator de conversão: $\mathrm{cal} / \mathrm{s} \rightarrow \mathrm{W}\left(4,184 \mathrm{~W}\right.$.s.cal $\left.{ }^{-1}\right)$; $\mathbf{C p}$ representa a capacidade calorífica da água (cal.g $\left.{ }^{-1} .{ }^{\circ} \mathrm{C}^{-1}\right), \mathbf{m}$ representa a massa da amostra de água (gramas), $\Delta \mathbf{T}$ representa a variação de temperatura observada $\left({ }^{\circ} \mathrm{C}\right)$ e $\mathbf{t}$ representa o tempo de irradiação (segundos).

\subsection{Verificação da reprodutibilidade de aquecimento do forno de micro-ondas}

Para verificar a reprodutibilidade de aquecimento do FMO foram realizados ensaios (em triplicata) de aquecimento de $100 \mathrm{~mL}$ de água em um béquer de $250 \mathrm{~mL}$, posicionado no local de maior incidência de radiação da cavidade do forno. O aquecimento, na potência máxima (100\%), foi realizado durante 120 segundos, medindo-se a temperatura em intervalos regulares de tempo de 10 segundos (BARBOZA et al., 2001).

\subsection{Determinação do teor de água pelo método do forno de micro-ondas}

Para secagem das cactáceas foi utilizado um forno de micro-ondas (FMO) doméstico da marca Electrolux, modelo MEF 28, com tensão de alimentação de $220 \mathrm{~V}$, capacidade de $18 \mathrm{~L}$, potência máxima de $700 \mathrm{~W}$ e frequência de $2450 \mathrm{MHz}$.

Após a determinação da região de maior incidência das micro-ondas dentro da cavidade do forno, calculado a potência real de trabalho e verificado a reprodutibilidade dos resultados apresentados pelo FMO utilizado neste estudo, iniciou-se a determinação do teor de água das amostras (cactáceas).

Para esta determinação utilizaram-se béqueres de $250 \mathrm{~mL}$ de polipropileno, onde foram acondicionadas $20 \mathrm{~g}$ de cada amostra. Os béqueres foram levados ao FMO com rampa de aquecimento utilizado para forragens, descrita na literatura (SOUZA et al., 2002). Depois de verificado a potência real do aparelho utilizado, o tempo de aquecimento utilizado em cada potência sugerida na rampa de aquecimento foi calculado de acordo com Equação 2.

$\operatorname{Tempo}(\min )=.\frac{T 1 . P 1}{P 2}$

Onde T1 representa o tempo recomendado no método (segundos), P1 representa a potência recomendada no método (w) e $\mathbf{P} 2$ representa a potência real de trabalho (w). 
No final do procedimento os béqueres foram transferidos para dessecador, para esfriarem, e em seguida as amostras foram pesadas. O teor de água das amostras foi calculado utilizando Equação 3. No interior do FMO foi colocado um béquer com $150 \mathrm{~mL}$ de água, com a finalidade de umedecer o ambiente, evitar a combustão das amostras e não causar danos ao aparelho. A água do béquer foi trocada a cada novo ensaio para evitar que a mesma entrasse em ebulição (SOUZA et al., 2002).

Teor de água $(\%)=\frac{m i-m f}{m i} \times 100$

Onde $\boldsymbol{m}_{\boldsymbol{i}}$ representa a massa inicial da amostra (gramas) e $\boldsymbol{m}_{\boldsymbol{f}}$ representa a massa da amostra seca (gramas).

\subsection{Determinação do teor de água pelo método padrão em estufa}

O teor de água foi determinado pelo método gravimétrico a partir de secagem direta em estufa a $105^{\circ} \mathrm{C}$, por 24 horas, em triplicata. Foi utilizada uma estufa de secagem e esterilização, marca Fanem, modelo 315 SE. Foram utilizados $20 \mathrm{~g}$ de matéria fresca de cada cactácea estudada e o teor de água foi calculado utilizando a Equação 3 (SILVA; FERREIRA; SOUZA, 2006).

\subsection{Análise dos Dados}

Os dados quantitativos foram trabalhados através da estatística descritiva (valores de média e desvio padrão). Após a verificação da normalidade dos dados (Kolmogorov Smirnov), as comparações dos valores de teor de água das cactáceas quanto ao método de determinação (estufa e FMO) dentro de cada tratamento da amostra (por separado, a saber: triturados e pedaços) foram feitas através do teste $t$ de Student. O nível de significância considerado em toda a análise foi $\mathrm{p}<0,05$. Os resultados foram apresentados na forma de tabelas (CRESPO, 2009; ZAR, 2010). O pacote estatístico utilizado foi o Statistica $@$ versão 8.0 .

\section{Resultados e discussão}

\subsection{Mapeamento do forno de micro-ondas}

O cloreto de cobalto (II) quando hidratado possui coloração rosa claro e quando desidratado torna-se azul. Esta mudança de coloração pode ser explicada por modificações que ocorrem na estrutura do complexo formado após o aquecimento. A variação da coloração possibilita um rápido mapeamento qualitativo do processo de secagem assistido por radiação micro-ondas oferecendo condições de visualizar a distribuição de radiação micro-ondas na cavidade do FMO (ROSINI et al., 2004). Os resultados obtidos no mapeamento utilizando a solução aquosa de $\mathrm{CoCl}_{2}$ podem ser observados nas Figuras 3 e 4.

Figura 3. Papel toalha absorvente embebido com a solução aquosa de $\mathrm{CoCl}_{2}(4 \% \mathrm{~m} / \mathrm{v})$, antes da irradiação com micro-ondas. Fonte: Arquivo pessoal. 


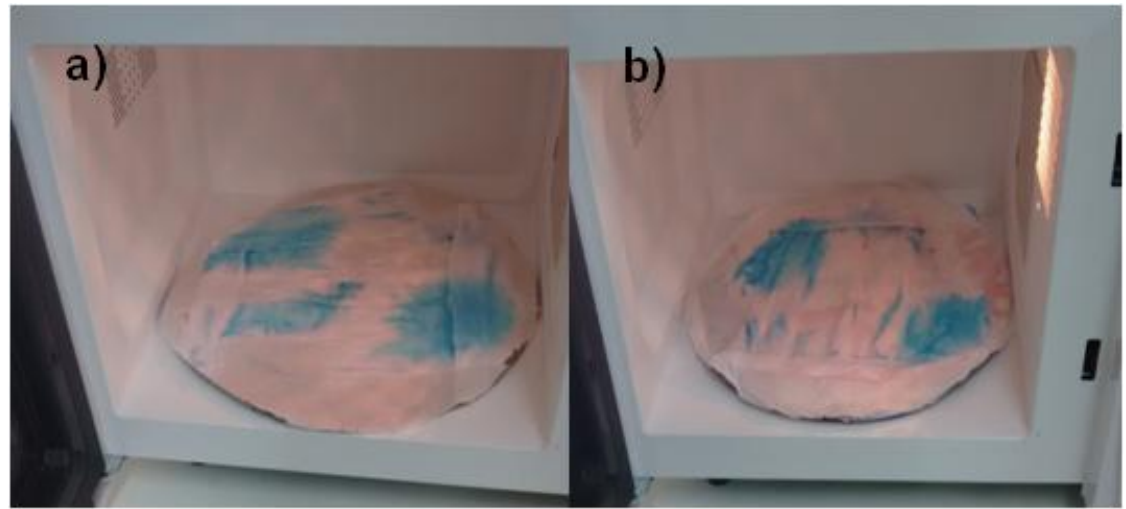

Figura 4. Coloração do papel toalha absorvente embebido com a solução aquosa de $\mathrm{CoCl}_{2}(4 \% \mathrm{~m} / \mathrm{v})$ : (a) após irradiação com prato fixo e (b) coloração após irradiação com prato girando. Fonte: Arquivo pessoal.

Nos pontos onde a incidência de radiação foi maior, pode-se observar uma coloração azul intensa. Diferenças significativas não foram observadas quando o experimento foi realizado com o prato fixo e com o prato girando. Verificou-se, portanto, que na região superior esquerda e inferior direita ocorreu a maior incidência de micro-ondas.

\subsection{Calibração do forno de micro-ondas}

Os resultados da variação de temperatura em relação à potência utilizada no aquecimento da água e da potência real calculada de acordo com equação (1) são apresentados na Tabela 1. Observou-se que a potência real calculada para o forno é crescente em função do aumento da temperatura, mas não corresponde ao valor relatado pelo fabricante no manual do aparelho. Barboza et al., (2001) em estudo de calibração de FMO também observaram resultados semelhantes, ou seja, divergências entre a potência real de trabalho e a potência descrita pelo fabricante.

Tabela 1. Valores da potência teórica e potência real de trabalho do FMO.

\begin{tabular}{c|c|c|c}
\hline $\begin{array}{c}\text { Potência } \\
(\mathbf{\%})\end{array}$ & $\begin{array}{c}\text { Variação de temperatura } \\
\left({ }^{\circ} \mathbf{C}\right)\end{array}$ & $\begin{array}{c}\text { Potência teórica } \\
(\mathbf{W})\end{array}$ & $\begin{array}{c}\text { Potência real } \\
(\mathbf{W})\end{array}$ \\
\hline 100 & 15,7 & 700 & 547 \\
\hline 80 & 11,2 & 560 & 389 \\
\hline 60 & 9,0 & 420 & 314 \\
\hline 40 & 6,0 & 280 & 209 \\
\hline 20 & 3,5 & 140 & 122 \\
\hline
\end{tabular}

A Figura 5 apresenta os resultados da calibração, potência teórica (\%) versus potência real (W), do FMO utilizado neste trabalho. 


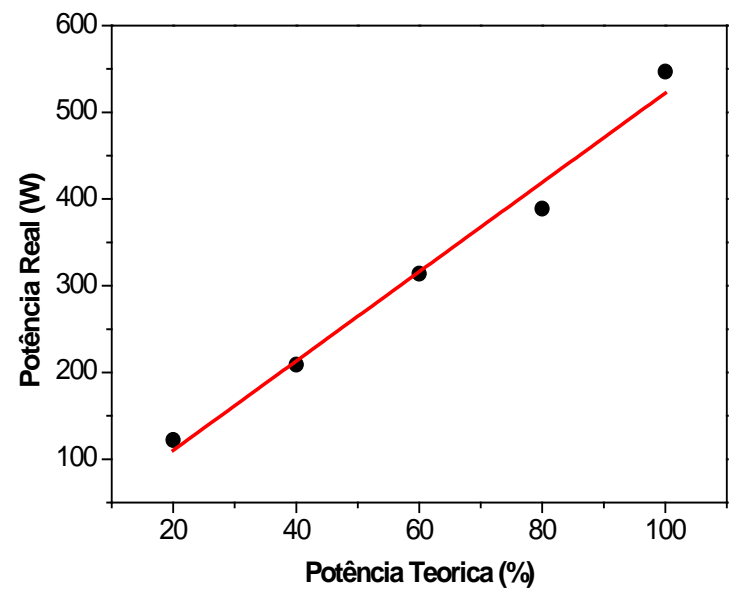

Figura 1. Gráfico: Curva de calibração da potência do FMO. Fonte: arquivo pessoal.

Com os dados da potência teórica (\%) e da potência real de trabalho (W) construiu-se a curva de calibração do FMO utilizado neste estudo. Os resultados mostram um fator de regressão $\left(\mathrm{R}^{2}\right)$ de 0,98 , dessa forma, é possível utilizar com confiabilidade o modelo linear proposto para calcular outros valores de potências reais a partir da Equação 4.

$P_{(\text {real })}=5,15 * P_{(\text {teórica) }}+7,08$

(4)

Após a verificação da potência real do FMO, o tempo de aquecimento utilizado em cada potência foi calculado de acordo com Equação 2. A seguinte rampa de secagem foi obtida: 4.49 minutos a 122 W, 7.19 minutos a $547 \mathrm{~W}$ e 6.38 minutos a $264 \mathrm{~W}$. Estes valores correspondem a 20, 100 e $50 \%$, respectivamente, da potência real do FMO utilizado (SOUZA et al., 2002).

\subsection{Verificação da reprodutibilidade do forno de micro-ondas}

Os resultados do teste de reprodutibilidade do FMO são apresentados na Figura 6. Observou-se que as curvas estão próximas, indicando que o forno reproduz bem a taxa de aquecimento.

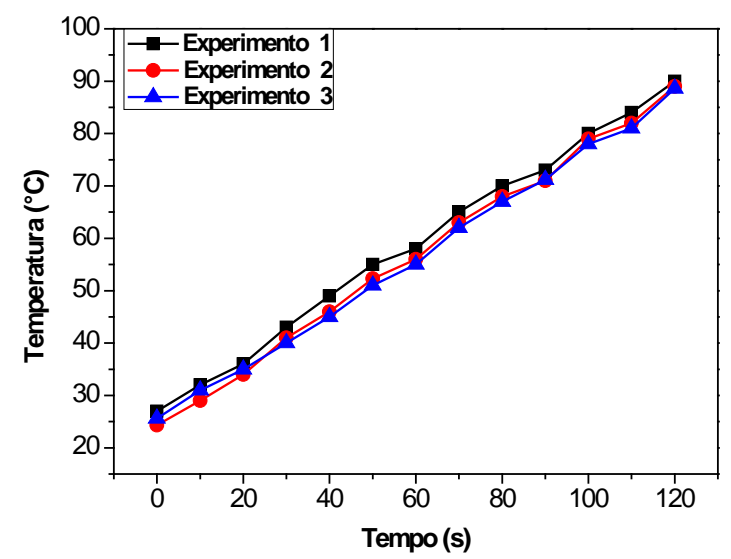

Figura 2. Gráfico: Curvas de aquecimento de $100 \mathrm{~mL}$ de água no FMO. Fonte: arquivo pessoal.

\subsection{Determinação do teor de água das cactáceas}

Os resultados referentes aos dois métodos utilizados para a determinação do teor de água obtidos para as cactáceas estudadas estão apresentados nas Tabelas 2 e 3, para as amostras trituradas e cortadas em pedaços, respectivamente. 
Tabela 2. Teor de água das cactáceas trituradas, determinadas por FMO e estufa.

\begin{tabular}{|c|c|c|c|}
\hline \multicolumn{4}{|c|}{ Teor de água (\%) } \\
\hline Amostras & Estufa & FMO & Estatística \\
\hline Palma forrageira & $69,31 \pm 1,20$ & $72,07 \pm 0,87$ & $\begin{array}{l}\mathrm{t}=-3,23 \\
\mathrm{GL}=4 \\
\mathrm{p}=0,03 *\end{array}$ \\
\hline Mandacaru & $90,20 \pm 0,80$ & $90,41 \pm 0,33$ & $\begin{array}{l}\mathrm{t}=-0,42 \\
\mathrm{GL}=4 ; \\
\mathrm{p}=0,70 \mathrm{Ns}\end{array}$ \\
\hline Xiquexique & $94,41 \pm 0,09$ & $91,38 \pm 0,13$ & $\begin{array}{l}\mathrm{t}=33,19 \\
\mathrm{GL}=4 ; \\
\mathrm{p}<0,03 *\end{array}$ \\
\hline Facheiro & $95,19 \pm 1,30$ & $94,1 \pm 0,95$ & $\begin{array}{l}\mathrm{t}=1,17 \\
\mathrm{GL}=4 ; \\
\mathrm{p}=0,31 \mathrm{Ns}\end{array}$ \\
\hline
\end{tabular}

* = diferença significativa $(\mathrm{p}<0,05)$; GL = grau de liberdade; Ns = não significativo.

Tabela 3. Teor de água das cactáceas cordadas em pedaços, determinadas por FMO e estufa.

\begin{tabular}{|c|c|c|c|}
\hline \multicolumn{4}{|c|}{ Teor de água (\%) } \\
\hline Amostras & Estufa & FMO & Estatística \\
\hline Palma forrageira & $69,82 \pm 0,09$ & $70,54 \pm 0,68$ & $\begin{array}{l}\mathrm{t}=-1,82 \\
\mathrm{GL}=4 \\
\mathrm{p}=0,14 \mathrm{Ns}\end{array}$ \\
\hline Mandacaru & $89,60 \pm 0,24$ & $90,89 \pm 0,19$ & $\begin{array}{l}\mathrm{t}=-7,30 \\
\mathrm{GL}=4 \\
\mathrm{p}<0,05 *\end{array}$ \\
\hline Xiquexique & $91,17 \pm 1,01$ & $93,08 \pm 1,09$ & $\begin{array}{l}\mathrm{t}=-2,23 \\
\mathrm{GL}=4 ; \\
\mathrm{p}=0,09 \mathrm{Ns}\end{array}$ \\
\hline Facheiro & $90,02 \pm 0,18$ & $92,37 \pm 0,44$ & $\begin{array}{l}t=-8,56 \\
G L=4 ; \\
p<0,05 *\end{array}$ \\
\hline
\end{tabular}

* = diferença significativa ( $<$ 0,05); GL = grau de liberdade; Ns = não significativo.

Os resultados obtidos na Tabela 2 mostram que os teores de água determinados pelos dois métodos nas amostras das cactáceas trituradas estão relativamente próximos. Quando comparada a secagem utilizando o FMO com o método convencional em estufa, percebe-se que os valores dos teores de água determinados para as cactáceas (mandacaru e facheiro) não diferem estatisticamente entre si. Observa-se que os resultados apresentados na Tabela 3, para as cactáceas cortadas em pedaços, a palma forrageira e o xiquexique apresentaram valores de teor de água estatisticamente iguais entre si e que os valores determinados pelo método do FMO foram maiores tanto para o mandacaru quanto para o facheiro, quando estes foram cortados em pedaços antes do processo de secagem. Resultados semelhantes foram encontrados em estudos realizados para determinação do teor de água em solos pelos métodos de FMO e pelo método padrão em estufa (ARAÚJO et al., 2004).

Borges et al., (2011), não observaram diferenças significativas entre os métodos padrão em estufa e FMO na secagem de folhas de alface, sendo o método utilizando o FMO mais viável para preparação da amostra por diminuir o tempo de preparo.

Vinholis et al., (2008) em seu estudo concluíram que o método utilizando o FMO para determinação do teor de água em alimentos, plantas e solo pode ser considerado eficaz em comparação aos métodos tradicionais de secagem, pois permite a obtenção de resultados satisfatórios com elevada qualidade e redução de tempo do processo. 


\title{
4. Conclusão
}

O mapeamento térmico do FMO é importante para garantir que o material esteja exposto a maior radiação possível. A potência real de trabalho do FMO é crescente em função do aumento da temperatura, sendo inferior ao valor relatado no manual pelo fabricante do aparelho, dessa forma a potência real deve ser determinada antes do procedimento experimental. O FMO utilizado neste estudo reproduz bem a taxa de aquecimento.

A determinação do teor de água utilizando o FMO apresenta-se como uma alternativa viável ao método convencional de secagem utilizando o método padrão em estufa, sendo as principais vantagens à redução no consumo de energia e a significativa redução no tempo necessário para secagem da amostra, pois, os resultados de secagem obtidos pelo método padrão em estufa utilizando um tempo de aproximadamente 24 horas a uma temperatura de $105{ }^{\circ} \mathrm{C}$ podem ser obtidos utilizando um tempo consideravelmente menor utilizando a radiação de micro-ondas que é de aproximadamente 20 minutos, dependendo do material estudado. Portanto, o método utilizando o forno de micro-ondas pode ser considerado rápido, seguro e preciso para determinação do teor de água em algumas cactáceas utilizadas para alimentação animal.

\section{Determination of water content of Cactaceas by Standard Methods in Greenhouse and Microwave}

\begin{abstract}
:
The determination of water content in green fodder and silage is one of the most widely used in research on fodder used for feeding. The difficulties encountered in this type of analysis usually are related to incomplete separation of the product water, the product decomposition and loss of volatile substances. This study aimed to compare the methods for determining the water content using the furnace microwave and standard oven method in four cactus: cactus (ficus-indica Mill), mandacaru (Cereus jamacaru), facheiro (Pilosocereus pachycladus) and xiquexique ( Pilosocereus gounellel). Once collected, the samples were treated (crushed and cut into pieces) and submitted to the two methods for determining the water content. The determination of the water content using the microwave oven is presented as a viable alternative to the conventional method of drying oven, the main advantages in reducing the energy consumption and a significant reduction in drying time which is 24-hour procedure using the stove and 18 minutes when the drying is performed by microwaves.
\end{abstract}

Keywords: Forage; Drying; Animal feed.

\section{Agradecimentos}

Os autores agradecem a CAPES pelo apoio financeiro.

\section{Referências bibliográficas}

ARAÚJ O, P. R. B.; FERREIRA, M. A.; BRASIL, L. H. A.; SANTOS, D. C.; LIMA, R. M. B.; VÉRAS, A. S. C.; SANTOS, M. V. F.; BISPO, S. V.; AZEVEDO, M. Substituição do milho por palma forrageira em dietas completas para vacas em lactação. Revista Brasileira de Zootecnia, v. 33, p. 1850-1857, 2004.

BARBOZA, A. C. R. N.; CRUZ, C. V. M. S.; GRAZIANI, M. B.; LORENZETII, M. C. F.; SABADINI, E. Aquecimento em forno de microondas / desenvolvimento de alguns conceitos fundamentais. Quimica Nova, v. 24, n. 6, p. 901-904, 2001. 
BORGES, B. M. M. N.; LUCAS, F. T.; MODESTO, V. C.; PRADO, R. M.; SILVA, E. S.; BRAOS, B. B. Métodos de determinação da matéria seca e dos teores de macronutrientes em folhas de alface. Revista Trópica - Ciências Agrárias e Biológicas, v. 5, n. 1, p. 12-16, 2011.

CRESPO, A. A. 2009. Estatística Fácil. 19a Edição. Editora Saraiva, São Paulo.

JOBIM, C. C.; NUSSIO, L. G.; REIS, R. A.; SCHMIDT, P. Avanços metodológicos na avaliação da qualidade da forragem conservada. Revista Brasileira de Zootecnia, v. 36, p. 101-119, 2007.

LACERDA, J .; FREITAS, K.; SILVA, J. Métodos De Microondas E Convencional: Determining Forage Dry Matter Using Microwave Oven and Conventional Method. Bioscience J ournal - Universidade Federal de Uberlândia, v. 25, p. 185-190, 2009.

ROSINI, F.; NASCENTES, C. C.; NÓBREGA, J. A. Experimentos didáticos envolvendo radiação microondas. Quimica Nova, v. 27, n. 6, p. 1012-1015, 2004.

SILVA, F. D. C.; FERREIRA, V. F.; SOUZA, M. C. B. V. Adaptação de forno de microondas doméstico para realização de reações de transesterificação sob refluxo e catálise for argilas. Quimica Nova, v. 29, n. 2, p. 376-380, 2006.

SOUZA, G. B. DE; NOGUEIRA, A. R. D. A.; RASSI NI , J. B. Determinação de matéria seca e umidade em solos e plantas com forno de microondas doméstico. Embrapa Pecuária Sudeste, 2002, 9p. (Embrapa Pecuária Sudeste. Circular Técnica, 33).

VINHOLIS, M. M. B.; SOUZA, G. B.; NOGUEIRA, A. R. A.; PRIMAVESI, O. Uso do microondas doméstico para determinação de matéria seca e do teor de água em solos e plantas : avaliação econômica , social e ambiental. Custos e @gronegócio on line, v. 4, n 2, p. 80-97, 2008.

ZAPPI, D.; TAYLOR, N.; SILVA, S. R.; MACHADO, M.; MORAES, E. M.; CALVENTE, A.; CRUZ, B.; CORREIA, D.; LAROCCA, J.; ASSIS, J. G.; AONA, L.; MENEZES, M. O. T.; MEIADO, M.; MARCHI, M. N.; SANTOS, M. R.; BELLINTANI, M.; COELHO, P.; NAHOUM, P. I.; RESENDE, S. PLANO DE AÇÃO NACI ONAL PARA A CONSERVAÃo DAS CACTÁCEAS. Brasília: Instituto Chico Mendes de Coservação da Biodiversidade, ICMBI O, 2011, 112p.

ZAR, J. H. 2010. Biostatistical Analysis. 5th Edition. Pearson Prentice Hall, Upper Saddle River, NJ , $944 \mathrm{pp}$. 